\title{
Comparison of Detection Rate of Root Canal Orifices of Maxillary First Molar Using Various Techniques: An in-vivo Study
}

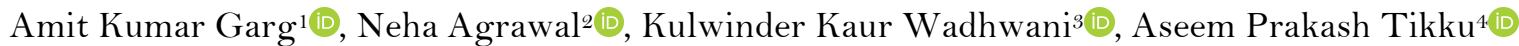

\begin{abstract}
'Department of Conservative Dentistry and Endodontics, Maharana Pratap College of Dentistry \& Research Centre, Gwalior \& Madhya Pradesh Medical Science University, Jabalpur, MP, India.

${ }^{2}$ Department of Periodontics and Community Dentistry, Dr. Z. A. Dental College, Aligarh Muslim University, Aligarh, UP, India. ${ }^{s}$ Department of Operative Dentistry, Faculty of Dental Science, King George's Medical University, Lucknow, UP, India.

${ }^{4}$ Department of Conservative Dentistry and Endodontics, Faculty of Dental Science, King George's Medical University, Lucknow, UP, India.
\end{abstract}

Correspondence: Neha Agrawal, Department of Periodontics and Community Dentistry, Dr. Z. A. Dental College, Aligarh Muslim University, Aligarh, UP, India. E-mail: dr.n_agrawal@yahoo.co.in

Academic Editor: Alessandro Leite Cavalcanti

Received: 15 May 2020 / Review: 05 August 2020 / Accepted: 17 August 2020

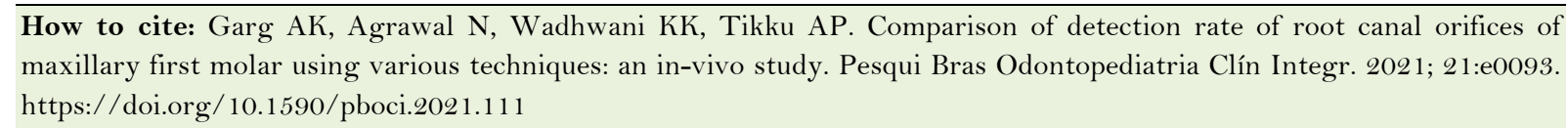

\begin{abstract}
Objective: To compare the detection rate of root canal orifices of maxillary first molar by various techniques in the Indian population. Material and Methods: A total of 50 maxillary 1st molar cases were selected and sequentially divided into four groups: Group I: Naked eye; Group II: Surgical loupe; Group III: Surgical operating microscope; and Group IV: Fluorescein sodium dye. After access opening, the number of root canal orifices was detected in all cases with these methods. Results: By naked eye and surgical loupe, a total of 171 root canal orifices were detected, by a surgical operating microscope, 176, and by fluorescein sodium dye, 177 root canal orifices were detected. The detection rate of root canal orifices is as follows: Group I $(96.61 \%)=$ Group II $(96.61 \%)<$ Group III $(99.44 \%)<$ Group IV $(100 \%)$ and detection rate of MB2 canal orifices Group I $(40 \%)=$ Group II $(40 \%)<$ Group III $(50 \%)<$ Group IV $(52 \%)$. No significant difference in the number of canal orifices detected could be seen for any of the comparisons. No significant difference was observed between the naked eye and surgical loupe techniques. Although the surgical operating microscope detected more root canal orifices, it did not have a significantly higher detection than the other two techniques. Conclusion: No significant difference was seen among various methods. However, the use of a surgical operating microscope and fluorescein sodium dye increased the detection rate of root canal orifices.
\end{abstract}

Keywords: Endodontics; Molar; Dental Pulp Cavity; Root Canal Therapy. 


\section{Introduction}

The major goal of root canal treatment is the thorough mechanical and chemical debridement of all root canals and their complete obturation with an inert filling material and a coronal filling preventing ingress of microorganisms [1]. One of the main reasons for the failure of root canal therapy is the lack of sufficient knowledge concerning the anatomy of teeth, both internal and external [2].

The maxillary first molars have been reported to have a root canal anatomy with maximum complexity and variations [3]. Because of this complexity, it has the highest endodontic failure rate, which often results from a missed second canal in the mesiobuccal 2 (MB2) root that remains undetected and, therefore, untreated [4].

The past decades have observed significant advances in the art and science of endodontics. The use of surgical headlamps and dental loupes has evolved into the use of a surgical operating microscope (SOM). Today, every challenge existing in the straight portion of the root canal system can be easily seen and often solved under the microscope, with magnification and coaxial illumination. The microscope has higher magnification in the range of 2.5-30x with better illumination using fibro optic technology $[5,6]$.

The use of a microscope facilitates the location and thereafter treatment of very fine canals, particularly the $\mathrm{MB} 2$ canal in maxillary molars [7,8]. The dental operating microscope has also been associated with obtaining better treatment results in various studies of endodontic surgery [9]. Recently, ophthalmic dyes have also been used in dentistry. The use of ultraviolet-induced fluorescence spectroscopy has studied in diagnosis, pulp and root canal location, as well as using fluorescent spectroscopy to measure the relative sealing efficiency of the root canal sealers [10].

The purpose of this study was to compare the detection rate of root canal orifices of Maxillary 1st Molar by the naked eye, surgical loupe, surgical operating microscope, and fluorescein sodium dye.

\section{Material and Methods}

Study Design and Sample

In this in vivo study, a total of 50 patients requiring root canal treatment of permanent maxillary 1 st molars were selected from the outpatients referred to the Department of Conservative Dentistry and Endodontics, Dental College, Lucknow (India). A thorough history, clinical examination and radiological examination were carried out before start of treatment so that systematically healthy patients were selected.

Medically compromised patients and molars with previous endodontic treatment, a deficient coronal structure, aberrant anatomy, and calcified canals were excluded from the study. Patients were selected irrespective of sex and socioeconomic status.

\section{Clinical Procedures}

A total of 50 teeth were included (divided into two subgroups) and two endodontists were involved in identifying the root canal orifice in assigned groups. Working independently, they set out to explore the root canal orifices to detect accessory mesial canals using a standardized sequence.

After injecting local anesthesia (Lignox 2\% A, Warren Indoco Remedies Ltd, Gandhi Nagar, Gujrat, India), a rubber dam (Hygenic Dental Dam kit, Coltene Whaledent, Inc., Cuyahoga Falls, OH, USA) was applied and coronal access was made with Endo Access bur and Endo-Z bur (Dentsply Maillefer, Ballaigues, Switzerland). Initially, the mesiobuccal, distobuccal and palatal canals were located. To detect additional canal orifices thorough probing of fissure between the mesiobuccal and palatal canals was done with endodontic 
explorer (DG-16 Ash Instruments, Dentsply, Gloucester, UK). Attempts were then made to negotiate the accessory mesial canals with size 06 K-type hand files (Dentsply Maillefer, Balleigue, Switzerland). When negotiation was unsuccessful, the isthmus was troughed apically with an L N bur (Dentsply Sirona, Milford, DE, USA) and slow speed handpiece to pursue the accessory canal deeper into the root. Irrigation with $1 \%$ $\mathrm{NaOCl}$ and a Stropko air irrigator (Sybron Endo) were used intermittently to optimize visibility.

Exploration of the groove connecting the canal orifices was performed with Kfile \#6, \#8 or \#10 (Dentsply Maillefer, Ballaigues, Switzerland). The existence of each orifice was recorded when a K-file \#8 or \#10 pushed into the orifice was able to stand by itself. Thus in this study, the word canal orifice stands for a true canal. The number of root canal orifices in each root detected by the naked eye was recorded in Group I (Figure 1).

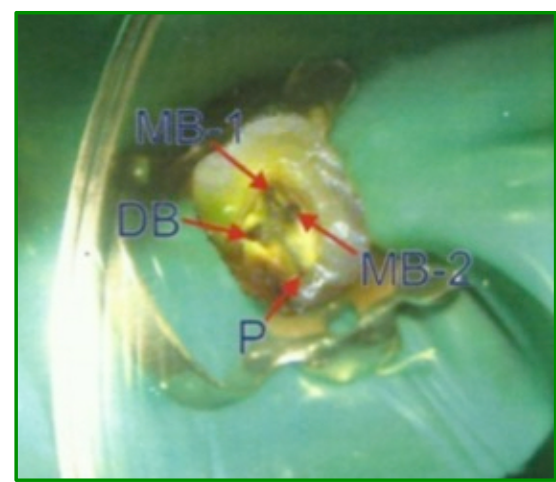

Figure 1. Naked eye view of canal orifices.

In the second stage, all the teeth were observed under a surgical loupe (2.5-3.0X) (Neitz BLS-3 3x Loupe, Activ Technology, LLC, Torrance, CA, USA). If dentin overhang over the orifice was present, this was removed with LN bur to find out another canal orifice and the number of canal orifices in each root was recorded in Group II. All the teeth were again observed through a surgical operating microscope - SOM (2.615.5X) (OPMI PROergo, Carl Zeiss, Germany) to detect canal orifice (Figure 2).

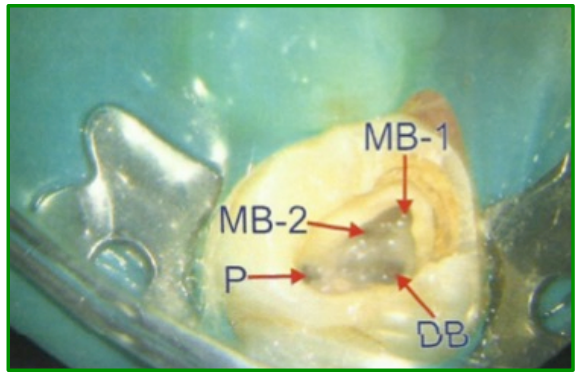

Figure 2. Canal orifices observed under surgical operating microscope.

If dentin overhang over the orifice was present, this was removed with $\mathrm{LN}$ bur to find out another orifice and the number of canal orifices in each root was recorded in Group III. In the third stage, the pulp chamber of the teeth was flooded with fluorescein sodium dye (Figure 3A) to detect canal orifices that might have been left undetected by naked eye, surgical loupe, and surgical operating microscope. After suctioning the excess dye, a blue curing light (with the SOM light turned off) was used to fluorescence the pulp tissue in the chamber. The canal orifice was readily located by the uptake of dye that emitted bright green fluorescence (Figure 3B), and the number of canal orifices in each root was recorded in Group IV. 


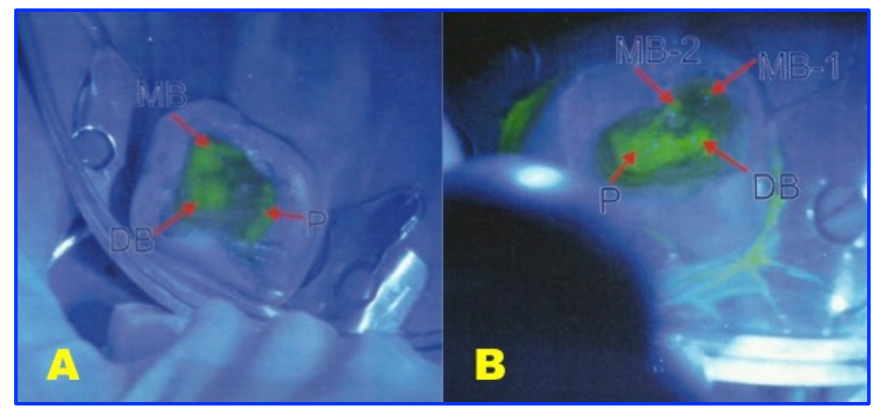

Figure 3. (A) Pulp chamber of the teeth was flooded with fluorescein sodium dye; (B) Fluorescence of tissue remnants in the canal orifices seen after penetration of fluorescein sodium dye.

\section{Data Analysis}

Data obtained was entered in an Excel sheet and transferred to SPSS 16.0 software (SPSS, Inc., Chicago, IL, USA) for the statistical analysis. A P-value less than 0.05 was considered statistically significant. The chi-square test was applied to find out the significant difference between various devices used to detect root canal orifices in maxillary first molar.

\section{Ethical Clearance}

Ethical clearance was obtained from the institutional review board (Protocol No. 129/Ethics/R.Cell11). Informed consent was obtained from the patient prior to the start of the study.

\section{Results}

As in this study, tooth clearing was not possible; hence the next best diagnostic technique, i.e., surgical operating microscope, was taken as a gold standard. Apart from the naked eye, surgical loupe and surgical operating microscope, fluorescein sodium dye was also taken as a test technique.

On using gold standard criteria (surgical operating microscope), mesiobuccal canal orifice (MB1), distobuccal canal orifice (DB1) and palatal canal orifice (P1) were seen in the entire sample. The mesiobuccal canal orifice $(\mathrm{MB} 2)$ was seen in 25 samples. Palatal $(\mathrm{P} 2)$ canal orifice was seen in one and distobuccal (DB2) canal orifice was seen in none of the samples. Through naked eye too, mesiobuccal canal orifice (MB1), distobuccal canal orifice (DB1) and palatal canal orifice (P1) were seen in all the samples. MB-2 canal orifice was seen in 20 samples. Palatal $(\mathrm{P} 2)$ canal orifice was seen in one, while distobuccal (DB2) canal orifice was not detected in any case. In the case of surgical loupes, mesiobuccal canal orifice (MB1), distobuccal canal orifice (DB1) and palatal canal orifice (P1) were seen in all the samples. MB-2 canal orifice was seen in 20 samples. Palatal ( $\mathrm{P} 2)$ canal orifice was seen in one, while distobuccal (DB2) canal orifice was not detected in any case. In case of fluorescein sodium dye, mesiobuccal canal orifice (MB1), distobuccal canal orifice (DB1) and palatal canal orifice $(\mathrm{P} 1)$ were seen in all the samples. MB-2 canal orifice was seen in 26 samples while Palatal (P2) canal orifice was seen in one and distobuccal (DB2) canal orifice was not detected in any case (Table 1).

Surgical operating microscope was found to be most effective, while fluorescein sodium dye was also found to be equally effective under in vivo conditions. Fluorescein sodium was found to be even improving upon the gold standard technique used in the study as the one case detected as false positive by this technique was found to be true on further exploration (Table 2 ). 
Table 1. Detection of root canal orifices of maxillary first molar using various techniques.

\begin{tabular}{|c|c|c|c|c|c|}
\hline Number & Root Canal Orifice & Naked Eye & Surgical Loupe & $\begin{array}{l}\text { Surgical Operating } \\
\text { Microscope } \\
\text { N }\end{array}$ & $\begin{array}{l}\text { Fluorescein } \\
\text { Sodium } \\
\text { N }\end{array}$ \\
\hline 1 & MB1 & 50 & 50 & 50 & 50 \\
\hline 2 & $\mathrm{MB} 2$ & 20 & 20 & 25 & 26 \\
\hline 3 & DB 1 & 50 & 50 & 50 & 50 \\
\hline 4 & $\mathrm{P} 1$ & 50 & 50 & 50 & 50 \\
\hline 5 & $\mathrm{P}_{2}$ & 1 & 1 & 1 & 1 \\
\hline 6 & $\mathrm{DB} 2$ & o & O & 0 & 0 \\
\hline
\end{tabular}

Table 2. Overall detection rate.

\begin{tabular}{lcccccccc}
$\begin{array}{c}\text { Root Canal } \\
\text { Orifices }\end{array}$ & \multicolumn{2}{c}{ Naked Eye } & \multicolumn{2}{c}{ Surgical Loupe } & \multicolumn{2}{c}{$\begin{array}{c}\text { Surgical Operating } \\
\text { Microscope }\end{array}$} & \multicolumn{2}{c}{$\begin{array}{c}\text { Fluorescein } \\
\text { Sodium }\end{array}$} \\
& $\mathrm{N}$ & $\%$ & $\mathrm{~N}$ & $\%$ & $\mathrm{~N}$ & $\%$ & $\mathrm{~N}$ & $\%$ \\
\hline Mesiobuccal & 70 & 92.11 & 70 & 92.11 & 75 & 98.68 & 76 & 100.00 \\
Distobuccal & 50 & 100.00 & 50 & 100.00 & 50 & 100.00 & 50 & 100.00 \\
Palatal & 51 & 100.00 & 51 & 100.00 & 51 & 100.00 & 51 & 100.00 \\
$\quad$ Total & 171 & 96.61 & 171 & 96.61 & 176 & 99.44 & 177 & 100.00 \\
\hline
\end{tabular}

Maximum detection rate for mesiobuccal canal orifice was seen for fluorescein sodium dye followed by surgical operating microscope, surgical loupe and naked eye. For distobuccal and palatal canal orifice, all three techniques had the same detection rate. The overall detection rate was also the maximum for fluorescein sodium dye (Table 3 ).

Table 3. Intergroup comparison.

\begin{tabular}{lcc}
\hline \multicolumn{1}{c}{ Comparison } & $\chi^{\mathbf{2}}$ & p-value \\
\hline Naked Eye $v$ s. Surgical Loupe & 0 & 1 \\
Naked Eye vs. Surgical Operating Microscope & -2.046 & 0.153 \\
Surgical Loupe vs. Surgical Operating Microscope & -2.046 & 0.153 \\
\hline
\end{tabular}

No significant difference in the number of canal orifices detected could be seen for any of the comparisons. No significant difference was observed between naked eye and surgical loupe techniques. Although the surgical operating microscope detected more root canal orifices, it did not have a significantly higher detection than the other two techniques in question.

\section{Discussion}

The success of root canal treatment (RCT) is entirely determined by thorough debridement, disinfection, and three-dimensional obturation of the complete root canal system. To achieve these objectives, it is essential to recognize the root canal configuration and additional canals [11].

In the present study, root canal orifices were more easily detected under SOM and fluorescein sodium dye than with surgical loupe or naked eye. Magnified views under illumination made it easier to recognize the dentin coverage over the orifice. As a result, dentin coverage could be removed precisely with LN-bur. The ability of clinician to locate root canal orifices largely depends on awareness and conviction of their existence. In the present study, the detection rate of root canal orifices is as follows: Group I (96.61\%) = Group II $(96.61 \%)<$ Group III $(99.44 \%)<$ Group IV $(100 \%)$ and detection rate of MB-2 canal orifices Group I $(40 \%)=$ Group II $(40 \%)<$ Group III $(50 \%)<$ Group IV $(52 \%)$. 
Thus it seemed that magnification of operating field provided by SOM was an important factor in successfully locating the MB-2 canals. Based on these results, more emphasis should be placed on the importance of using magnification for locating the MB-2 canal orifices. Buhrley et al. [12] also detected an increased number of mesiobuccal canals with the help of dental loupe and SOM. Previous authors also suggested that magnification and illumination increased the detection rate of root canal orifices $[8,13,14]$. The use of ophthalmic dye increased the results from $50 \%(\mathrm{SOM})$ to $52 \%$. The use of ophthalmic dye helps in marking the pulp tissue in canal orifices to facilitate the location of canals in both conventional and retreatment cases. This is of even greater significance in teeth with full coverage where the orientation markers of the natural tooth can't be seen and previously endodontically treated teeth. Thus, ophthalmic dye played an important role in the location of the canal orifice. It should be practiced clinically to conserve tooth structure, which will help for the longevity of the treatment [10].

Besides, this many case reports presented the complex root canal anatomy of maxillary 1st molar. Cases of maxillary 1st molar with unusual morphology have also been reported, for example, maxillary 1st molar with six canals, three canals in mesiobuccal root and a case of unusual maxillary 1st molar with two palatal canals within a single root [15-17]. The present study also contributes to an understanding of root canal system in maxillary 1 st molars.

In the present study, the detection rate of root canal orifices of maxillary 1st molar increased in mesiobuccal root and no improvement was seen in distobuccal and palatal root. Thus, these results supported that mesiobuccal root is more complex than distobuccal and palatal root. The magnification and illumination increased the detection rate of root canal orifices, but the increase was statistically not significant.

Thus, we observed that by scheduling adequate clinical time, by using the proper magnification and detection instruments aids, modifying access opening, by having a thorough knowledge of how and where to search for MB-2, and with the experience, the rate of location could be increased in maxillary 1st molars. It is suggested that for successful endodontic treatment, a surgical operating microscope should be practiced to achieve a higher degree of skill.

\section{Conclusion}

Magnification and illumination increased the detection rate of root canal orifices, but the increase was statistically not significant and the anatomy of MB root was much more complex as compared to distobuccal and palatal root.

\section{Authors' Contributions}

$\begin{array}{llll}\text { AKG } & \text { (D) https://orcid.org/0000-0003-1561-7866 } & \text { Conceptualization, Methodology, Investigation, Resources and Writing - Original Draft. } \\ \text { NA } & \text { (D) https://orcid.org/0000-0001-6034-9675 } & \text { Methodology, Validation, Writing - Review and Editing and Visualization. } \\ \text { KKW } & \text { (D) https://orcid.org/o000-0003-3309-3410 } & \text { Conceptualization, Methodology, Visualization, Supervision and Project Administration. } \\ \text { APT } & \text { (D) https://orcid.org/o000-0003-0368-552X } & \text { Conceptualization, Methodology, Writing - Review and Editing, Visualization and Supervision } \\ \text { All authors declare that they contributed to critical review of intellectual content and approval of the final version to be published. }\end{array}$

\section{Financial Support}

None.

\section{Conflict of Interest}

The authors declare no conflicts of interest. 


\section{Data Availability}

The data used to support the findings of this study can be made available upon request to the corresponding author.

\section{References}

[1] De Moor RJ, Deroose CA, Calberson FL. The radix entomolaris in mandibular first molars: an endodontic challenge. Int Endod J 2004; 37(11):789-99. https://doi.org/10.1111/j.1365-2591.2004.00870.x

[2] Pécora JD, Woelfel JB, Sousa Neto MD, Issa EP. Morphologic study of the maxillary molars. Part II: internal anatomy. Braz Dent J 1992; 3(1):53-7.

[3] Vertucci FJ, Haddix JE, Britto LR. Tooth Morphology and Access Cavity Preparation. In: Cohen S, Hargreaves KM, editors. Pathways of the Pulp. 9th ed. St. Louis: Mosby Elsevier; 2006. 203p.

[4] Smadi L, Khraisat A. Detection of a second mesiobuccal canal in the mesiobuccal roots of maxillary first molar teeth. Oral Surg Oral Med Oral Pathol Oral Radiol Endod 2007; 103(3):e77-81. https://doi.org/10.1016/j.tripleo.2006.10.007

[5] Pecora G, Andreana S. Use of dental operating microscope in endodontic surgery. Oral Surg Oral Med Oral Pathol Oral Radiol Endod 1993; 75(6):751-8. https://doi.org/10.1016/0030-4220(93)90435-7

[6] Weller RN, Niemezyk SP, Kim S. Incidence and position of the canal isthmus. Part I. mesiobuccal root of the maxillary first molar. J Endod 1995; 2 1(7):380-3. https://doi.org/10.1016/s0099-2399(06)80975-1

[7] Alaçam T, Tinaz AC, Genç O, Kayaoglu G. Second mesiobuccal canal detection in maxillary first molars using microscopy and ultrasonics. Aust Endod J 2008; 34(3):106-9. https://doi.org/10.1111/j.1747-4477.2007.00090.x

[8] Das S, Warhadpande MM, Redij SA, Jibhkate NG, Sabir H. Frequency of second mesiobuccal canal in permanent maxillary first molars using the operating microscope and selective dentin removal: A clinical study. Contemp Clin Dent 2015; 6(1):74-8. https://doi.org/10.4103/0976-237X.149296

[9] Setzer FC, Kohli MR, Shah SB, Karabucak B, Kim S. Outcome of endodontic surgery: a meta-analysis of the literature - Part 2: Comparison of endodontic microsurgical techniques with and without the use of higher magnification. J Endod 2012; 38(1):1-10. https://doi.org/10.1016/j.joen.2011.09.021

[10] Nallapati S, Glassman G. Ophthalmic dyes for root canal location. Endod Pract 2004; 7:2 1-6.

[11] Tzeng LT, Chang MC, Chang SH, Huang CC, Chen YJ, Jeng JH. Analysis of root canal system of maxillary first and second molars and their correlations by cone beam computed tomography. J Formos Med Assoc 2020; 119(5):968-73. https://doi.org/10.1016/j.jfma.2019.09.012

[12] Buhrley LJ, Barrows MJ, BeGole EA, Wenckus CS. Effect of magnification on locating the MB-2 canal in maxillary molars. J Endod 2002; 28(4):324-7. https://doi.org/10.1097/00004770-200204000-00016

[13] Karapinar-Kazandag M, Basrani BR, Friedman. The operating microscope enhances detection and negotiation of accessory mesial canals in mandibular molars. J Endod 2010; 36(8):1289-94. https://doi.org/10.1016/j.joen.2010.04.005

[14] Coutinho Filho T, La Cerda RS, Gurgel Filho ED, de Deus GA, Magalhães KM. The influence of the surgical operating microscope in locating the mesiolingual canal orifice: a laboratory analysis. Braz Oral Res 2006; 20(1):5963. https://doi.org/10.1590/s1806-83242006000100011

[15] Kishan KV, Das D, Chhabra Z, Rathore VPS, Remy V. Management of maxillary first molar with six canals using operating microscope. Indian J Dent Res 2018; 29(5):683-86. https://doi.org/10.4103/ijdr.IJDR_722_16

[16] Ayranci LB, Arslan H, Topcuoglu HS. Maxillary first molar with three canal orifices in mesiobuccal root. J Conserv Dent 2011; 14(4):436-37. https://doi.org/10.4103/0972-0707.87222

[17] Johal S. Unusual maxillary first molar with two palatal canals within a single root: a case report. J Can Dent Assoc $2001 ; 67(4): 211-4$. 